JURNAL SISFOTENIKA

Vol. 10 No. 1, Januari 2020

p-ISSN: 2087-7897; e-ISSN : 2460-5344

DOI : $10.30700 /$ jst.v10i1.511

\title{
Sistem Pendukung Keputusan Menentukan Bibit Padi Terbaik Menggunakan Metode Gap Kompetensi
}

\section{Decision Support Systems Determine the Best Rice Seeds Using the Competence Gap Method}

\author{
Elvis Pawan*1, ${ }^{* 1}$ gung Jasuma ${ }^{2}$, Achmad Yusron Arif ${ }^{3}$, Kusrini $^{4}$ \\ ${ }^{1}$ Program Studi Teknik Informatika, STIMIK Sepuluh Nopember Jayapura Tlp (0967) 533799 \\ ${ }_{2,3,4}$ Magister Teknik Informatika, Universitas Amikom Yogyakarta Tlp (0274) 884201 \\ e-mail: *11 elvispawan09@gmail.com, ${ }^{2}$ agung.jasuma@ students.amikom.ac.id, \\ 3achmadyusronarif@gmail.com, ${ }^{4}$ kusrini@amikom.ac.id
}

\begin{abstract}
Abstrak
Pemerintah sedang mempersiapkan Indonesia mencapai swasembada pangan, akan tetapi perlu kita ketahui bahwa persolaan utama yang akan menghambat cita-cita tersebut tercapai adalah jika produksi hasil pertanian padi menurun terutama di daerah terpencil. Ini diakibatkan karena kurangnya pengetahuan petani dalam menentukan bibit padi yang cocok untuk ditaman pada lahan pertanian. Penelitian ini diharapkan dapat membantu petani secara khusus yang belum mengerti menentukan bibit padi yang baik. Selain itu hasil penelitian ini dapat membantu pemerintah mewujudkan swasembada pangan di Indonesia. Dalam merancang SPK ini menggunakan metode Gap Kompetensi dengan memasukkan beberapa kriteria seperti, produksi padi perhektar, ketahanan terhadap penyakit, harga bibit, batas tanam, dan kebutuhan tanah, kriteria tersebut akan diolah sesuai aturan metode Gap Kompetensi untuk menghasilkan sebuah rekomendasi bibit terbaik. Penelitian ini menghasilkan SPK, kriteria utama digunakan ketahanan terhadap penyakit dan harga bibit yang diberikan nilai prioritas sebesar $70 \%$, kriteria lainnya sebesar 30\%. Berdasarkan kriteria tersebut diperoleh tiga varietas padi yang direkomendasikan oleh sistem yaitu pertama jenis Kalimasada, kedua Inpasari 42 GSR dan ketiga jenis Mapan P-05. Bagi peneliti selanjutnya diharapkan dapat membandingkan beberapa metode serta menggabungkan kedalam sistem pakar untuk tingkat akurasi yang lebih baik.
\end{abstract}

Kata kunci-SPK, Gap Kompetensi, Bibit, Padi

\begin{abstract}
Government is preparing Indonesia to achieve food self-sufficiency, but we need know the main process that will hamper these ideals achieved if the production of paddy agriculture decreases, especially remote areas. This is due to lack of knowledge of farmers in determining which rice seeds are suitable for planting on agricultural land. This research is expected to help farmers specifically who do not understand the determination of good rice seeds. In addition, the results of this study can help the government realize food self-sufficiency in Indonesia. In designing this SPK using the Competence Gap method by including several criteria such as rice production per hectare, disease resistance, seed prices, planting limits, and land requirements, these criteria will be processed according to the rules of the Competence Gap method to produce the best seed recommendation. This study resulted in SPK, the main criteria used for disease resistance and the price of seeds given a priority value of 70\%, another criterion of $30 \%$. Based these criteria, three rice varieties recommended by DSS, Kalimasada, both
\end{abstract}


Inpasari 42 GSR and the three types of Mapan P-05. The next researcher expected able to compare several methods and combine them into expert system for better accuracy.

Keywords - DSS, Competency Gap, Seeds, Rice

\section{PENDAHULUAN}

Salah satu kebijakan pemerintah pada pembangunan bidang pertanian khususnya tanaman pangan bertujuan untuk melestarikan swasembada pangan [1]. Beras yang bersumber dari padi merupakan salah satu makanan pokok bagi masyarakat Indonesia [2]. Sebagian besar mata pencaharian penduduk di Indonesia adalah bertani, tanaman pertanian yang paling banyak diolah adalah padi [2]. Sebagai Negara agraris negara Indonesia, merupakan Negara yang kaya akan sumber daya alam. Hingga kini mayoritas penduduk Indonesia telah memanfaatkan sumber daya alam untuk menunjang kebutuhan hidupnya dan salah satunya ialah menggantungkan hidupnya pada sektor pertanian [3]. Namun sering kali masyarakat atau petani kesulitan dalam menentukan bibit yang cocok untuk ditanam [3]. Beberapa alasan inilah yang mendorong dilakukannya penelitian ini.

Beberapa penelitian menentukan bibit tanaman yang baik telah dilakukan akan tetapi menggunakan metode yang berbeda pada penelitian ini, beberapa metode yang digunakan diantaranya metode Analytical Hierarchy Process (AHP), Technique for Order of Preference by Similarity to Ideal Solution (TOPSIS), Simple Additive Weighting (SAW) dan beberapa metode lainnya. Adapun penelitian mencari bibit tanaman padi terbaik dengan menggunakan metode AHP telah dilakukan dan memiliki kesimpulan bahwa metode AHP baik untuk digunakan dalam menentukan bibit tanaman padi terbaik akan tetapi pada penelitian tersebut memiliki beberapa kelemahan seperti kesimpulan SPK tidak memiliki wisdom dan sistem yang dibangun tidak sampai dengan implementasi melainkan hanya sebuah rancangan [3]. Sedangkan penelitian ini sampai pada tahap implementasi kedalam aplikasi SPK.

Penelitian tentang menentukan bibit padi unggul menggunakan metode Simple Additive Weighting (SAW) memiliki kesimpulan bahwa dengan adanya sistem pendukung keputusan menggunakan metode SAW maka petani mimiliki panduan dalam menentukan bibit unggul akan tetapi pada penelitian tersebut memiliki kelemahan yakni wisdom serta rekomendasi bibit unggul yang dihasilkan dari SPK ini tidak ditampilkan [4]. Sedangkan penelitian ini memberikan hasil rekomendasi dan wisdom yang akan digunakan oleh petani sebagai acuan dalam menentukan bibit padi yang akan ditanam, ini merupakan hasil akhir dari sistem pendukung keputusan yang dirancang.

Penelitian tentang penentuan varietas padi terbaik menggunakan metode AHP dan TOPSIS telah dilakukan oleh peneliti sebelumnya dan memiliki kesimpulan akurasi kecocokan antara keluaran sistem dan pendapat ahli sebesar $83.33 \%$ akan tetapi kelemahan pada penelitian tersebut hanya melakukan perangkingan [5]. Perbedaan pada penelitian yang ini yaitu tidak hanya dilakukan perangkingan pada sistem namun terdapat hasil rekomendasi berupa laporan yang dapat dicetak dari sistem, yang dapat digunakan petani sebagai rekomendasi untuk menentukan atau membeli bibit padi yang di inginkan.

Selain itu metode Gap Kompetensi telah beberapa kali diteliti oleh pakar terdahulu akan tetapi pada kasus yang berbeda misalnya penelitian penggunaan metode profile matching untuk penunjang keputusan kenaikan jabatan pada sebuah instansi pemerintah pada penelitian ini memberikan rekomendasi pegawai yang akan dipilih sebagai kandidat yang paling cocok untuk mendapatkan kenaikan jabatan, akan tetapi kelemahan penelitian tersebut tidak diimplementasikan kedalam bentuk aplikasi SPK sehingga perhitungan dan penentuan dilakukan secara manual [6]. Perbedaan penelitian ini dengan penelitian sebelumnya adalah hasil perhitungan manual akan di implementasikan kedalam aplikasi SPK sehingga benar-benar dapat dimanfaatkan oleh masyarakat atau petani. 
Penelitian yang menggunakan bantuan metode profile matching pemilihan kandidat pejabat structural pada sebuah instansi pemerintahan di kota Tarakan memiliki kesimpulan bahwa dengan memanfaatkan metode profile matching maka penilaian kandidat dapat dilakukan oleh sistem sehingga dapat membantu mengatasi masalah yang muncul yang sebelumnya dilakukan secara manual sehingga sistem ini dapat membantu meminimalisir terjadinya keputusan secara subjektif [7]. Perbedaan pada penelitian yang dilakukan adalah dalam hal implementasi pada penelitian terdahulu mengambil objek pada pemilihan kandidat pejabat struktural pada instansi pemerintahan sedangkan penelitian ini objeknya dilakukan pada penentuan bibit tanaman padi terbaik, hal yang dipertimbangkan sebagai acuan dari penelitian terdahulu menyatakan bahwa metode profile matching dapat membantu untuk memutuskan jalan keluar sebuah kasus dan terhindar dari hal-hal yang bersifat subjektif.

Penelitian lain dengan menggunakan metode profile matching pada pemindahan posisi karyawan dalam sebuah perusahaan, kesimpulan pada penelitian ini bukan berupa rekomendasi atau wisdom melainkan sebuah harapan pada masa yang akan datang, selain itu pengujian pada SPK yang dibangun tidak dijelaskan secara eksplisit [8]. Perbedaan pada penelitian ini bahwa kesimpulan berupa rekomendasi sebagai hasil akhir dari sistem SPK yang dirancang

Penelitian pemilihan marketing terbaik pada sebuah perusahaan perbankan menggunakan metode profile matching pada penelitian ini menyimpulkan bahwa metode profile matching dapat memberikan bantuan untuk menentukan seorang marketing officer yang terbaik akan tetapi kelemahan pada penelitian tersebut adalah pengujian tidak dilakukan [9]. Perbedaaan pada penelitian ini dilakukan dua pengujian yaitu pengujian terhadap sistem dan pengujian terhadap output untuk benar-benar mengetahui akurasi dari hasil penelitian.

\section{METODE PENELITIAN}

\subsection{Alur Penelitian}

Dalam melakukan penelitian terdiri dari beberapa tahapan penting yang digambarkan dan dijelaskan seperti terlihat pada Gambar 1 Alur Penelitian. Hal ini mempunyai tujuan agar para pembaca dapat benar-benar memahami langkah-langkah dalam membuat sebuah sistem pendukung keputusan menggunakan metode Gap Kompetensi. 


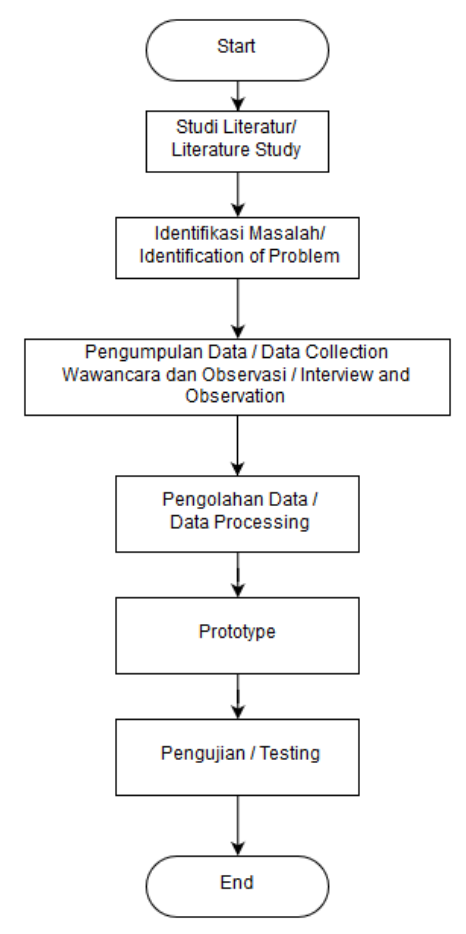

Gambar 1. Alur Penelitian

Berdasarkan langkah-langkah pada Gambar 1 Alur Penelitian, dijelaskan bahwa ada enam tahapan penting dalam melakukan penelitian ini, langkah pertama adalah studi literatur pada tahap ini peneliti mempelajari hal-hal yang berkaitan dengan topik pada penelitian, adapun sumber-sumber literatur berupa makalah, jurnal, hasil penelitian tesis, prosiding, arsip dan artikel yang memiliki ciri atau kesamaan topik yang dibahas. Langkah kedua dengan melakukan identifikasi masalah bertujuan untuk mengetahui permasalahan yang sedang terjadi dan memfokuskan penelitian pada kasus yang akan dipecahkan atau diselesaikan. Langkah ketiga pengumpulan data yang berkaitan dengan topik yang dibahas pada penelitian ini, data dikumpulkan dari berbagai sumber baik dari para ahli ataupun dari literatur-literatur. Langkah ke empat melakukan pengolahan data yang telah dikumpulkan serta melakukan perhitungan manual dengan mengikuti aturan metode Gap Kompetensi, hal tersebut bertujuan agar memudahkan pemindahan kedalam prototype atau aplikasi SPK. Langkah ke lima pembuatan prototype atau aplikasi untuk memperoleh representasi dari hasil penelitian dan dapat digunakan sebagai pembanding perhitungan manual. Langkah ke enam melakukan pengujian atau testing terhadap akurasi hasil penelitian.

\subsection{Gap Kompetensi}

Gap merupakan sebuah perbedaan antara profile yang dimiliki oleh masing-masing alternatif dengan profile standar. Hal tersebut dapat dilihat pada persamaan 1 [10] [11].

Gap $=$ Profile Atribut - Profile Target

Hasil akhir dari sebuah gap kompetensi adalah rangking varietas padi yang akan ditanam, Penentuan rangkin berpatokan pada perhitungan kriteria yang diinputkan user pada sistem. 


\subsection{Perancangan Sistem}

a. Data Flow Diagram (DFD)

Data flow diagram ialah data yang dimanfaatkan untuk menggambarkan langkahlangkah atau proses yang terjadi pada sistem yang sedang dirancang untuk dikembangkan. Dengan memakai model DFD aliran atau arus data dapat terdeteksi dengan mudah. Pada penggunaan model DFD dimulai dari diagram konteks selanjutnya diagram berjenjang, diagram level 1 sampai pada diagram terperinci, hal tersebut dapat disesuaikan dengan kompleksitas SPK yang dikembangkan [12]. Adapun diagram konteks pada SPK yang dirancang dapat dilihat pada Gambar 2.

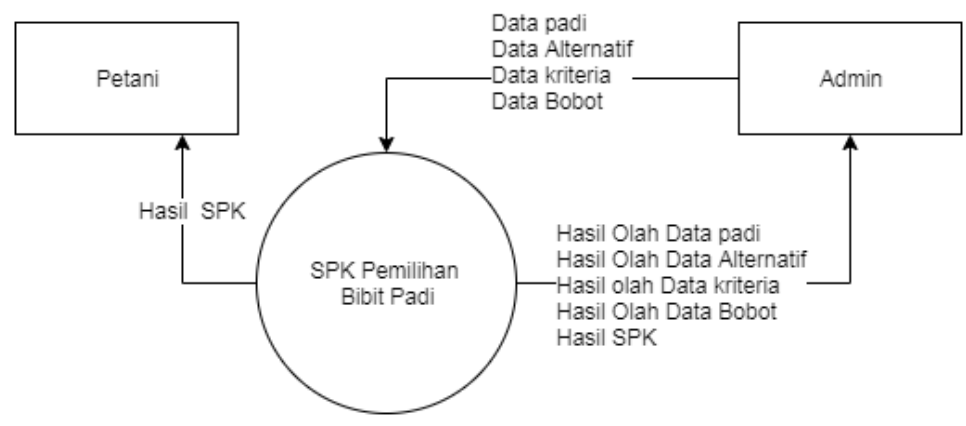

Gambar 2. Diagram Konteks

Gambar 2. Diagram Menjelaskan aliran atau arus data didalam sistem SPK yang dirancang sebagai contoh Admin dapat menginputkan pada sistem bebera bentuk data misalnya data alternative, data kriteria, data bobot, dan data padi sehingga sistem akan mengirimkan kembali hasil pengolahan data yang telah di inputkan oleh admin, baik itu berupa data yang di tampilkan di sistem maupun data yang dapat dicetak.

b. Perancangan Basis Data

Setelah pembuatan DFD selanjutnya mendesain rancangan basis data yang digunakan pada aplikasi SPK, adapun rancangan basis data Sistem pendukung keputusan Penentuan bibit padi terbaik menggunakan metode Gap Kompentesi dapat dilihat pada gambar 3. Rancangan Basis data SPK.
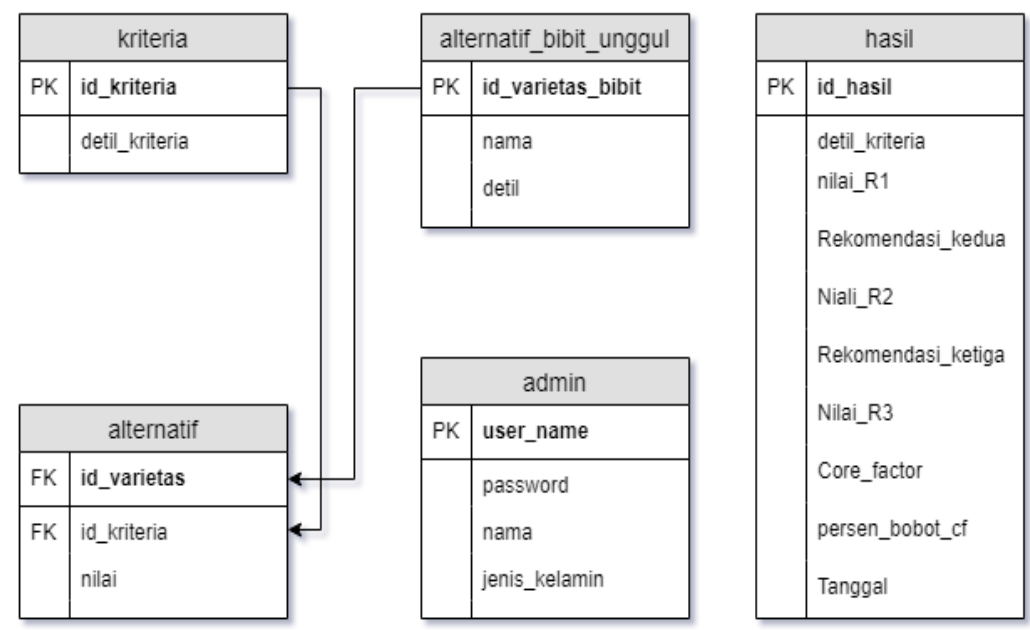

Gambar 3. Rancangan Basis Data SPK 
Pada Gambar 3 menjelaskan terdapat lima tabel yang digunakan pada SPK ini diantaranya adalah tabel kriteria, alternatif, varietas_bibit_unggul, tabel admin dan tabel hasil. Terdapat tiga tabel yang berelasi yaitu tabel kriteria berelasi ke tabel alternative dengan Id_kriteria pada tabel kriteria sebagai Primary Key (PK) dan id_kriteria pada tabel alternatif sebagai foreign key (FK). Tabel varietas_bibit_unggul berelasi ke tabel alternatif dengan id_varietas_bibit sebagai primary key (PK) pada tabel varietas_bibit_unggul dan id_varietas pada tabel alternatif sebagai foreign key (FK). Sedangkan tabel admin dan tabel hasil berdiri sendiri dan tidak berelasi ke tabel lainnya.

\section{HASIL DAN PEMBAHASAN}

Hal yang paling penting dalam keberhasilan panen adalah menggunakan bibit yang baik dalam bercocok tanaman, itu dapat berdampak positif terhadap hasil panen karena dengan menggunakan bibit yang baik dapat mengurangi potensi tanaman terserang hama, panen dapat meningkat sampai dengan rata-rata 11 ton dalam satu hektar lahan, batas tanam juga dapat dilakukan beberapa kali, serta baik ditanam pada kondisi rata-rata $\mathrm{pH}$ tanah. Hal tersebut tentu sangat diharapkan oleh setiap petani akan tetapi permasalahan yang terjadi dilapangan ialah hanya sebaian kecil petani yang dapat menentukan jenis padi yang cocok ditanam.

Sistem pendukung keputusan dirancang agar dapat membantu seorang user untuk mengambil sebuah tindakan yang bermanfaat, sistem pendukung keputusan yang dirancang menggunakan metode Gap Kompetensi dengan memasukkan beberapa kriteria yang sering dijumpai dilapangan. Dengan demikian dengan adanya sistem pendukung keputusan ini diharapkan penentuan bibit yang baik tidak lagi menjadi hal yang sulit bagi petani. Dalam melakukan analisis pada penelitian ini menggunakan data serta fakta yang dijumpai dilapangan.

\subsection{Daftar Varietas Bibit}

Data varietas bibit padi yang telah diperoleh dan digunakan pada penelitian ini dapat dilihat pada tabel 1 varietas bibit.

\section{Tabel 1. Varietas Bibit}

\begin{tabular}{ll}
\hline \multicolumn{1}{c}{ Nama Bibit } & \multicolumn{1}{c}{ Deskripsi } \\
Inpasari 42 GSR & $\begin{array}{l}\text { Varietas inbrida keluaran tahun 2016, rasanya enak dan pulen luar biasa, kerontokannya } \\
\text { pun mudah sekali. Potensi hasilnya mencapai 7,11 ton }\end{array}$ \\
\hline Sertani 13 & $\begin{array}{l}\text { Sertani } 13 \text { merupakan jenis padi dari MSP. Popularitasnya begitu meluas dari Sabang } \\
\text { sampai Merauke. Sertani 13 adalah jenis terbaik yaitu 13A, 13B, dan 13C. }\end{array}$ \\
\hline Mapan P-05 & $\begin{array}{l}\text { Padi hibrida merupakan unggulan berkualitas,Keunggulan utamanya adalah bobot tiap } \\
\text { gabah yang tinggi dengan hasil }>8 \text { ton / ha. }\end{array}$ \\
\hline Padjadjaran & $\begin{array}{l}\text { Padi padjadjaran ialah varietas keluaran 2018. Padi ini menjadi padi dengan hasil } \\
\text { tertinggi untuk varietas yang dikembangkan pemerintah selama ini. potensi } \\
\text { produktivitas 11 ton / ha, dengan rata-rata hasil 7,8 ton / ha. }\end{array}$ \\
\hline Kabir 07 & Kabir 07 adalah galur lokal Aceh.Hasil rata-rata diatas 8 ton / hektar. \\
\hline Inpari 43 GSR & $\begin{array}{l}\text { Varietas ini mempunyai gelar GSR (Green Super Rice) ini mampu memproduksi sampai } \\
10 \text { ton/ha. }\end{array}$ \\
\hline M400 & $\begin{array}{l}\text { Mempunyai hasil hingga 400 bulir / malai menjadikan jenis padi ini bisa menghasilkan } \\
\text { rata-rata diatas } 8 \text { ton / hektar dan potensi } 11 \text { ton. Selain usianya pendek hanya 90 harian } \\
\text { m400 lebih mudah dalam hal perawatan. }\end{array}$ \\
\hline IPB 3S & $\begin{array}{l}\text { Padi ini merupakan hasil penelitian ahli Pertaian Bogor ini mempunyai potensi hasil di } \\
\text { kisaran 10 ton lebih dengan rata-rata hasil 7 ton/ha. }\end{array}$ \\
\hline
\end{tabular}




\begin{tabular}{ll} 
PIM 1 & $\begin{array}{l}\text { Tinggi tanaman padi ini hampir } 2 \text { meter, banyak orang yang menyukainya karena } \\
\text { hasilnya yang banyak. Dalam satu malai dapat mencapai } 600 \text { bulir. }\end{array}$ \\
\hline Kalimasada & $\begin{array}{l}\text { Potensi hasilnya pun sangat lumayan hingga } 12 \text { ton dengan rata-rata hasil mencapai } 8,5 \\
\text { ton / hektar. Padi satu ini sangat mudah perawatannya dan lebih tahan penyakit. }\end{array}$
\end{tabular}

Pada tabel 1 varietas padi yang digunakan untuk merancang sistem ini sebanya sepuluh jenis yaitu Inpasari 42 GSR, Sertani 13, Mapan P-05, Padjadjaran, Kabir 07, Inpari 43 GSR, M400, IPB 3S, PIM 1, Kalimasada. Jenis bibit padi tersebut berasal dari berbagai daerah di Indonesia.

\subsection{Alternative}

Pada penelitian ini memiliki nilai alternative pada setiap varietas atau jenis padi adapun nilai alternative dapat dilihat pada tabel 2 tabel alternative.

Tabel 2. Tabel Alternative

\begin{tabular}{|c|c|c|c|c|c|}
\hline Alternative & $\begin{array}{l}\text { Produksi Padi } \\
\text { Perhektar }\end{array}$ & $\begin{array}{l}\text { Ketahanan } \\
\text { terhadap } \\
\text { penyakit }\end{array}$ & Harga Bibit & $\begin{array}{l}\text { Batas Tanam } \\
\text { Bibit }\end{array}$ & $\begin{array}{l}\text { Kebutuhan } \\
\text { Tanah }\end{array}$ \\
\hline Inpasari 42 GSR & $\begin{array}{l}>8 \text { ton/ hektar } \&<=10 \\
\text { ton/ hektar }\end{array}$ & $\begin{array}{l}\text { Kurang (Tahan } \\
<2 \text { jenis } \\
\text { penyakit) }\end{array}$ & $<30 \mathrm{rb} / \mathrm{Kg}$ & $\begin{array}{l}\text { Kualitas tetap jika } \\
\text { ditanam lebih dari } \\
1 \mathrm{x}\end{array}$ & PH 6 \\
\hline Sertani 13 & $>10$ ton / perhektar & $\begin{array}{l}\text { Kurang (Tahan } \\
<2 \text { jenis } \\
\text { penyakit) }\end{array}$ & $>=60 \mathrm{rb} / \mathrm{Kg}$ & $\begin{array}{l}\text { Kualitas kurang } \\
\text { jika ditanam lebih } \\
\text { dari 1x }\end{array}$ & PH 6 \\
\hline
\end{tabular}

Pada tabel 3.2 merupakan nilai alternative yang dimiliki oleh jenis varieras padi sebagai contoh Inpasari 42 GSR memiliki alternative yaitu lebih besar dari 8 ton/ha, kurang tahan terhadap penyakit, harga bibit dibawah $30 \mathrm{ribu} / \mathrm{kg}$, kualitas buruk jika ditanam lebih dari satukali, dan tumbuh di lahan yang memiliki pH 6.

\subsection{Bobot Kriteria}

Dalam meracang sistem pendukung keputusan menggunakan metode Gap Kompetensi menggunakan beberapa kriteria yang dapat dijadikan sebagai pedoman untuk menentukan bibit terbaik dan sesuai dengan lahan ataupun kebutuhan tanam. Adapun kriteria yang digunakan dapat dilihat pada tabel 3 Bobot.

Tabel 3. Bobot Kriteria

\begin{tabular}{llll}
\hline \multicolumn{1}{c}{ Kriteria } & \multicolumn{1}{c}{ Nilai =1 } & \multicolumn{1}{c}{ Nilai $=\mathbf{2}$} & \multicolumn{1}{c}{ Nilai $=\mathbf{3}$} \\
\hline Produktivitas Padi & $<=8$ ton / hektar & $\begin{array}{l}>8 \text { ton/ hektar dan }<=10 \text { ton/ } \\
\text { hektar }\end{array}$ & $>10$ ton /hektar \\
\hline Ketahanan Penyakit & $\begin{array}{l}\text { Kurang (Tahan }<2 \text { jenis } \\
\text { penyakit) }\end{array}$ & $\begin{array}{l}\text { Sedang (tahan } 2 \text { jenis } \\
\text { penyakit) }\end{array}$ & $\begin{array}{l}\text { Baik (tahan }>2 \text { jenis } \\
\text { penyakit) }\end{array}$ \\
\hline Harga Bibit & $>=60 \mathrm{rb} / \mathrm{kg}$ & $<60 \mathrm{rb} / \mathrm{kg}$ dan $>=30 \mathrm{rb} / \mathrm{kg}$ & $<30 \mathrm{rb} / \mathrm{kg}$ \\
\hline Batas Tanam & $\begin{array}{l}\text { Kualitas sangat buruk jika } \\
\text { ditanam lebih dari } 1 \mathrm{kali}\end{array}$ & $\begin{array}{l}\text { Kualitas kurang jika ditanam } \\
\text { lebih dari } 1 \text { kali }\end{array}$ & $\begin{array}{l}\text { Kualitas tetap jika ditanam } \\
\text { lebih dari } 1 \text { kali }\end{array}$ \\
\hline Kebutuhan tanah & PH 5 & PH 6 & PH 7 \\
\hline
\end{tabular}

Dengan memperhatikan tabel 3 terdapat lima kriteria yang digunakan untuk menentukan bibit padi terbaik kriteria pertama adalah produktivitas padi, kedua ketahanan terhadap penyakit, ketiga harga bibit keempat batas tanam bibit dan kelima adalah kebutuhan bibit terhadap tanah. Untuk memperoleh nilai target maka pada setiap kriteria diberikan nilai sebagai contoh jika Produktivitas padi mencapai rata-rata lebih dari 10 ton perhektar maka nilai 
target yang diberikan adalah 3, sedangkan jika 8 sampai 10 ton perhektar diberikan nilai target adalah 2 dan jika lebih kecil dari 8 ton perhektar maka nilai target adalah 1.

\subsection{Mencari Selisih Alternative dengan Target Ideal}

Untuk mencari selisih nilai (Gap) menggunakan persamaan Gap = Profile Atribut -Profile Target, sebagai contoh jika user memilih kriteria ketahanan terhadap penyakit dan harga bibit sebagai prioritas dalam menentukan varietas bibit, dengan nilai prioritas sebanyak 70 $\%$ dan kriteria lainnya mendapat nilai sebanyak 30\% hal tersebut di ilustrasikan pada tabel 4 Target Ideal

Tabel 4. Target Ideal

\begin{tabular}{llc}
\multicolumn{1}{c}{ Kriteria } & \multicolumn{1}{c}{ Kebutuhan } & Nilai \\
\hline Produksi Padi & $>8$ ton/ hektar dan $<=10$ ton/ hektar & 2 \\
\hline Ketahanan terhadap Penyakit & Kurang (Tahan $<2$ jenis penyakit) & 1 \\
\hline Harga Bibit & $<60 \mathrm{rb}$ per KG \&\& $>=30$ rb per KG & 2 \\
\hline Batas Tanam Bibit & Kualitas tetap jika ditanam lebih dari 1x & 3 \\
\hline Kebutuhan Tanah & PH 7 & 3 \\
\hline
\end{tabular}

Pada tabel 4 merupakan ilustrasi antara kriteria yang tersedia, kebutuhan user serta nilai pada setiap kriteria. Kriteria prioritas adalah ketahanan terhadap penyakit dengan kebutuhan user varietas bibit tahan terhadap penyakit kurang dari dua, sehingga dengan kriteria tersebut diberikan nilai $=2$, kriteria prioritas lainnya adalah harga bibit dengan harga minimal $30 \mathrm{rb} / \mathrm{kg}$ dan maksimal harga kurang dari $60 \mathrm{rb} / \mathrm{kg}$ sehingga kriteria tersebut diberikan nilai $=2$, dari kedua kriteria tersebut diberikan nilai prioritas sebesar $70 \%$ sedangkan kriteria lainnya diberikan nilai prioritas $30 \%$.

\subsection{Selisih Nilai (Gap)}

Selisih yang diperoleh menggunakan rumus Gap = Profile Atribut - Profile Target dapat dilihat pada tabel 5 Selih Nilai (Gap).

Tabel 5. Selisih Nilai (Gap)

\begin{tabular}{lccccc}
\hline Alternative & $\begin{array}{c}\text { Produksi } \\
\text { Padi / } \\
\text { Hektar }\end{array}$ & $\begin{array}{c}\text { Ketahanan } \\
\text { terhadap } \\
\text { Penyakit }\end{array}$ & Harga Bibit & $\begin{array}{c}\text { Batas } \\
\text { Tanam Bibit }\end{array}$ & $\begin{array}{c}\text { Kebutuhan } \\
\text { Tanah }\end{array}$ \\
\hline Inpasari 42 GSR & 0 & 0 & 1 & 0 & -1 \\
\hline Sertani 13 & 2 & 0 & -1 & -1 & -1 \\
\hline Mapan P-05 & 1 & 2 & 1 & -2 & -1 \\
\hline Padjadjaran & 1 & 2 & 1 & 0 & 0 \\
\hline Kabir 07 & -1 & 1 & 1 & -2 & -1 \\
\hline Inpari 43 GSR & 1 & 1 & -1 & -1 & 0 \\
\hline M400 & 0 & 2 & -1 & 0 & -1 \\
\hline IPB 3S & 1 & 2 & -1 & -1 & 0 \\
\hline PIM 1 & 1 & 2 & 0 & -2 & 0 \\
\hline Kalimasada & 0 & 0 & 0 & -1 & 0 \\
\hline
\end{tabular}

Setelah mengetahui selisih nilai, selisih tersebut dikonvesi menjadi nilai baru dengan ketentuan jika 0 maka nilai baru $=3$, jika 1 maka nilai baru $=2,5$, jika -1 maka nilai baru $=2$, jika 2 maka nilai baru $=1,5$ dan jika selisih nilai -2 maka nilai baru $=1$.

\subsection{Nilai Baru}

Hasil konversi dari tabel selisih nilai (Gap) pada tabel 3.4 diperoleh nilai baru seperti pada tabel 6 dibawah ini. 
Tabel 6. Nilai Baru

\begin{tabular}{lccccc}
\hline Alternative & $\begin{array}{c}\text { Produksi } \\
\text { Padi / } \\
\text { Hektar }\end{array}$ & $\begin{array}{c}\text { Ketahanan } \\
\text { terhadap } \\
\text { Penyakit }\end{array}$ & Harga Bibit & $\begin{array}{c}\text { Batas } \\
\text { Tanam Bibit }\end{array}$ & $\begin{array}{c}\text { Kebutuhan } \\
\text { Tanah }\end{array}$ \\
\hline Inpasari 42 GSR & 3 & 3 & 2.5 & 3 & 3 \\
\hline Sertani 13 & 2 & 3 & 2 & 2 & 2 \\
\hline Mapan P-05 & 1.5 & 3 & 2.5 & 1 & 2 \\
\hline Padjadjaran & 2.5 & 1.5 & 2.5 & 3 & 3 \\
\hline Kabir 07 & 2 & 2.5 & 2.5 & 1 & 3 \\
\hline Inpari 43 GSR & 2.5 & 2.5 & 2 & 2 & 2 \\
\hline M400 & 3 & 1.5 & 2 & 3 & 3 \\
\hline IPB 3S & 2.5 & 1.5 & 2 & 2 & 3 \\
\hline PIM 1 & 2.5 & 1.5 & 3 & 2 & 3 \\
\hline Kalimasada & 3 & 3 & 3 & & 2 \\
\hline
\end{tabular}

Pada tabel 6 merupakan nilai baru yang bermanfaat untuk menghitung nilai core factor dan secondary factor sebagai contoh varietas padi Inpasari 42 GSR memiliki 5 kriteria dengan nilai baru produksi padi/ hektar $=3$, ketahanan terhadap penyakit $=3$, harga bibit $=2,5$, batas tanam bibit=3 dan kebutuhan tanah sebesar 3 .

\subsection{Perhitungan dan Pengelompokan Core dan Secondary Factor}

Hasil nilai baru yang terdapat pada tabel 6 selanjutnya dilakukan perhitungan mencari nilai core factor dan Secondary Factor, untuk memperoleh hasil rangking atau rekomendasi bibiy yang terpilih sebagai prioritas dalam memilih bibit. Hal tersebut dapat dilihat pada tabel 7 Hasil Rangking

Tabel 7. Hasil Rangking

\begin{tabular}{lcccccc}
\hline Alternative & $\begin{array}{c}\text { Core } \\
\text { Factor }\end{array}$ & $\begin{array}{c}\text { Secondary } \\
\text { Factor }\end{array}$ & $\begin{array}{c}\text { Nilai Core } \\
\text { Factor }\end{array}$ & $\begin{array}{c}\text { Nilai } \\
\text { Secondari } \\
\text { Factor }\end{array}$ & Hasil & Rangking \\
\hline Inpasari 42 GSR & 2.75 & 3 & 1.925 & 0.9 & 2.825 & 2 \\
\hline Sertani 13 & 2.5 & 2 & 1.75 & 0.6 & 2.35 & 3 \\
\hline Mapan P-05 & 2.75 & 1.5 & 1.925 & 0.45 & 2.375 & 2.25 \\
\hline Padjadjaran & 2 & 2.83 & 1.4 & 0.85 & 2.25 & \\
\hline Kabir 07 & 2.5 & 1.66 & 1.75 & 0.5 & 2.325 & \\
\hline Inpari 43 GSR & 2.25 & 2.5 & 1.575 & 0.75 & 2.025 & \\
\hline M400 & 1.75 & 2.66 & 1.225 & 0.8 & 1.975 \\
\hline IPB 3S & 1.75 & 2.5 & 1.225 & 0.75 & 2.225 & \\
\hline PIM 1 & 2.25 & 2.16 & 1.575 & 0.65 & 2.9 \\
\hline Kalimasada & 3 & 2.66 & 2.1 & 0.8 & \\
\hline
\end{tabular}

Pada table 7 merupakan rekomendasi atau wisdom yang dihasilkan dari sistem pendukung keputusan yang telah dirancang, dengan memilih kriteria ketahanan terhadap penyakit dan harga bibit, sebagai kriteria prioritas dan diberikan nilai prioritas sebesar $70 \%$, sedangkan kriteria lainnya diberikan nilai prioritas sebesar $30 \%$.

Dengan mengikuti aturan Gap kompetensi maka sistem pendukung keputusan memberikan 3 jenis varietas padi yang bisa ditanam, rekomendasi pertama adalah jenis bibit Kalimasada, rekomendasi kedua jenis Inpasari 42 GSR, dan rekomendasi ketiga adalah Mapan $\mathrm{P}-05$.

3.8 User Interface 
Untuk memanfaatkan sistem yang telah dibuat diawali dengan menentukan nilai target yang dapat dibuat atau diinput melalui modul menentukan target ideal seperti pada gambar 4 .

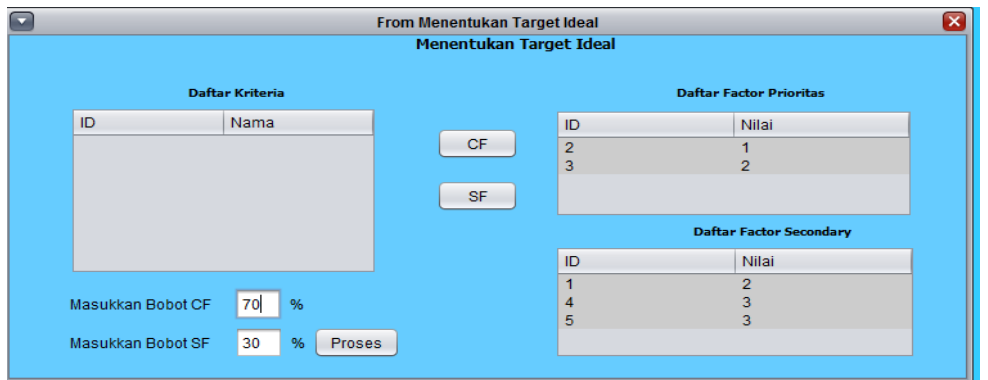

Gambar 4. Modul Menetukan Target Ideal

Pada gambar 4 user dapat memilih kriteria yang sesuai kebutuhan untuk menjadi $\mathrm{CF}$ (core factor) dan SF (Secondary Factor), selain itu user akan diminta mengisikan bobot CF berupa besaran presentasi nilai yang akan diambil untuk core factor atau kriteria utama, sedangkan bobot SF akan otomatis terisi dengan nilai 100 dikurang bobot $\mathrm{CF}$.

Data yang telah di inputkan akan di proses mengikuti aturan gap kompetensi dan selanjutnya diperoleh rekomendasi dari SPK, seperti pada gambar 5.

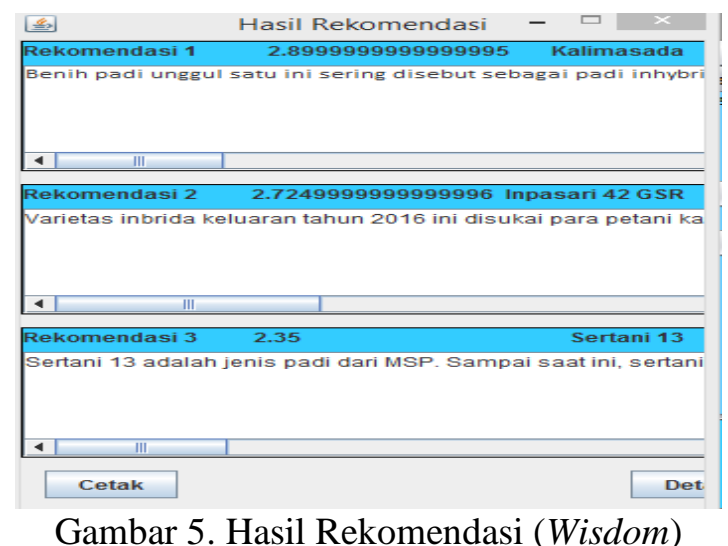

Pada gambar 5 menampilkan 3 varietas bibit padi terbaik beserta detail informasi pada masingmasing varietas bibit padi tersebut. Tiga varietas padi tersebut yang akan dijadikan rekomendasi varietas bibit yang sebaiknya di tanam.

\subsection{Pengujian}

Pengujian sistem bertujuan untuk mengetahui sistem pendukung keputusan dapat bekerja sesuai dengan tujuan perancangan.

\section{a. Black Box Testing}

Black box testing merupakan suatu metode pengujian perangkat lunak, melalui pengamatan terhadap hasil eksekusi melalui data uji serta memperhatikan fungsionalitas aplikasi perangkat lunak. Pada tabel 8 Hasil uji coba menggunakan metode black box testing pada sistem pendukung keputusan yang telah dirancang.

Tabel 8. Black Box Testing

\begin{tabular}{lllc}
\hline No & \multicolumn{1}{c}{ Skenario Pengujian } & \multicolumn{1}{c}{ Hasil Yang Diharapkan } & \multicolumn{1}{c}{ Status } \\
\hline 1 & $\begin{array}{l}\text { Pada Form Login memasukkan user } \\
\text { name dan password sesuai dengan } \\
\text { data yang terdapat pada database }\end{array}$ & $\begin{array}{l}\text { Login Sukses dan menuju pada form } \\
\text { menu utama }\end{array}$ & Valid/ sukses \\
\hline
\end{tabular}




\begin{tabular}{|c|c|c|c|}
\hline 2 & $\begin{array}{l}\text { Form login di isi user name dan } \\
\text { password yang tidak terdapat pada } \\
\text { database }\end{array}$ & $\begin{array}{l}\text { Terdapat pemberitahuan username atau } \\
\text { password salah dan tetap berada pada } \\
\text { laman login }\end{array}$ & Valid/Sukses \\
\hline 3 & $\begin{array}{l}\text { Pada Sistem dapat dilakukan input } \\
\text { dan menampilkan varietas padi }\end{array}$ & $\begin{array}{l}\text { Sistem dapat menyimpan dan me- } \\
\text { nam } \neg \text { pil } \neg \text { kan data varietas padi }\end{array}$ & Valid/Sukses \\
\hline 4 & $\begin{array}{l}\text { Memasukkan atau memilih kri-teria } \\
\text { dan memberikan nilai pri-oritas } \\
\text { sesuai dengan keinginan user }\end{array}$ & $\begin{array}{l}\text { Sistem dapat menampilkan reko- } \\
\text { mendasi jenis atau varietas padi yang } \\
\text { akan ditanam }\end{array}$ & Valid/Sukses \\
\hline 5 & $\begin{array}{l}\text { Menekan tombol proses sebelum nilai } \\
\text { prioritas di isikan }\end{array}$ & $\begin{array}{l}\text { Menampilkan pemberitahuan untuk } \\
\text { mengisi nilai prioritas terlebih dahulu }\end{array}$ & Valid/Sukses \\
\hline 6 & $\begin{array}{l}\text { Menampilkan } 3 \text { rekomendasi varietas } \\
\text { padi dengan nilai tertinggi }\end{array}$ & $\begin{array}{l}\text { Menampilkan } 3 \text { data varietas padi yang } \\
\text { memiliki nilai akhir tertinggi }\end{array}$ & Valid/Sukses \\
\hline
\end{tabular}

Pada tabel 8 memperlihatkan pengujian yang telah dilakukan terhadap prototype sistem pendukung keputusan yang telah dibuat. Pada masing-masing modul dilakukan pengujian berdasarkan kebutuhan fungsional, meskipun semua modul telah diuji akan tetapi hanya ditampilkan beberapa tindakan yang dilakukan pada modul yang dijadikan sebagai contoh, dan semua mendapatkan hasil yang valid atau sukses.

\section{b. Pengujian Output}

Setelah pembuatan prototype sistem pendukung keputusan selanjutnya dilakukan pengujian terhadap output software. Pengujian dilakukan dengan cara memasukkan data kriteria pada secara manual pada microsoft excel selanjutnya data yang sama di input pada sistem pendukung keputusan, apabila perhitungan manual dan perhitungan melalui sistem memiliki kesamaan maka pengujian berhasil, sebaliknya apabila berbeda maka pengujian gagal. Untuk memperjelas hasil pengujian dapat dilihat pada tabel 9 dibawah ini.

Tabel 9 Pengujian Output

\begin{tabular}{|c|c|c|c|c|}
\hline Pengujian & Nama Kriteria & Perhitungan Manual & $\begin{array}{c}\text { Perhitungan } \\
\text { Sistem }\end{array}$ & Keterangan \\
\hline Kasus 1 & $\begin{array}{l}\text { Core Factor : } 70 \% \\
\text { 1.Harga Bibit } \\
\text { 2. Ketahanan Terhadap Penyakit } \\
\text { Secondary Factor } \\
\text { 1. Produksi Padi } \\
\text { 2. Batas Tanam } \\
\text { 3. Kebutuhan Tanah }\end{array}$ & $\begin{array}{l}\text { 1. Kalimasada } \\
\text { 2. Inpasari } 42 \text { GSR } \\
\text { 3. Mapan P-05 }\end{array}$ & $\begin{array}{l}\text { 1. Kalimasada } \\
\text { 2. Inpasari } 42 \text { GSR } \\
\text { 3. Mapan P-05 }\end{array}$ & Berhasil \\
\hline Kasus 2 & $\begin{array}{l}\text { Core Factor: } 60 \% \\
\text { 1. Harga Bibit } \\
\text { 2. Batas Tanam } \\
\text { 3. Kebutuhan tanah } \\
\text { Secondary Factor } \\
\text { 1. Produksi Padi } \\
\text { 2. Ketahanan Terhadap Penyakit }\end{array}$ & $\begin{array}{l}\text { 1. Kalimasada } \\
\text { 2. Inpasari } 42 \mathrm{GSR} \\
\text { 3. Inpari } 43\end{array}$ & $\begin{array}{l}\text { 1. Kalimasada } \\
\text { 2. Inpasari } 42 \text { GSR } \\
\text { 3. Inpari } 43 \text { GSR }\end{array}$ & Berhasil \\
\hline Kasus 3 & $\begin{array}{l}\text { Core Factor: } 65 \% \\
\text { 1. Harga Bibit } \\
\text { 2. Produksi Padi } \\
\text { Secondary Factor } \\
\text { 1. Batas Tanam } \\
\text { 2. Ketahanan Terhadap Penyakit } \\
\text { 3. Kebutuhan Tanah }\end{array}$ & $\begin{array}{l}\text { 1.Inpasari } 42 \\
\text { 2. Kalimasada } \\
\text { 3.M400 }\end{array}$ & $\begin{array}{l}\text { 1. Inpasari } 42 \text { GSR } \\
\text { 2. Kalimasada } \\
\text { 3. Inpari } 43 \text { GSR }\end{array}$ & Berhasil \\
\hline
\end{tabular}

Pada tabel 9 merupakan hasil pengujian output antara sistem dan perhitungan manual sebagai contoh pada kasus pertama harga bibit dan ketahanan terhadap penyakit menjadi core factor dan produksi padi, batas tanam, serta kebutuhan tanah mencadi secondary factor, antara 
perhitungan manual dan sistem memiliki output yang sama sehingga pengujian dinyatakan berhasil.

c. Pengujian User Acceptence Test

Pengujian dengan dimaksudkan dapat memberikan gambaran apakah sistem pendukung keputusan ini dapat dimanfaatkan sesuai dengan kebutuhan, dan dapat menyelesaikan permasalahan dengan baik. Pengujian user acceptance test dapat dilihat pada gambar 6 .

\section{Grafik Pegujian User Acceptance Test}

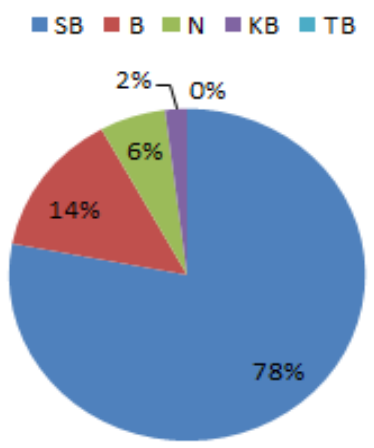

Gambar 6. Pengujian User Acceptence Tes

Pada gambar 6 merupakan pengujian yang dilakukan terdahap lima orang responden yang bertugas sebagai administrator, jawaban yang diperoleh sebanyak 78\% menjawab sangat benar (SB) dan $14 \%$ menjawab benar (B), 6\% netral $(\mathrm{N}), 2 \%$ kurang benar $(\mathrm{KB})$ dan $0 \%$ menjawab tidak benar (TB).

\section{KESIMPULAN}

Dari penelitian ini peneliti dapat menarik beberapa kesimpulan diantaranya adalah sebagai berikut :

a. Sistem pendukung keputusan menggunakan metode gap kompetensi dapat memeberikan rekomendasi jenis atau varietas yang cocok ditanam berdasarkan kriteria yang di inputkan pada sistem.

b. Berdasarkan kriteria batas tanam dan harga bibit dengan nilai prioritas sebanyak $70 \%$ dan kriteria lain mendapat nilai prioritas sebanya 30\% maka SPK memberikan tiga jenis padi yang cocok untuk ditanam, diantaranya Jenis kalimasada, Inpasari 42 GSR dan Mapan P-05.

\section{SARAN}

Pada penelitian ini penulis menyarankan beberapa hal kepada peneliti selanjutnya diantaranya sebagai berikut:

a. Untuk mengetahui akurasi dari metode gap kompetensi sebaiknya dilakukan penelitian dengan membandingkan beberapa metode, dan menggabungkan SPK dengan sistem pakar.

b. Dalam penelitian selanjutnya sabaiknya aplikasi dibuat dengan berbasis website atau android agar dapat di akses oleh banyak pihak yang membutuhkan.

DAFTAR PUSTAKA

Vol. 10, No. 1, Januari 202035 
[1] N. F. Mayalibit, Suwarto, E. Rusdiyana, and A. Wijianto, "Rice Farmers Attitude To Superior Certified Seeds," J. Sustain. Agric., vol. 2, no. 2, pp. 116-125, 2017.

[2] A. Praba et al., "Klasifikasi Prioritas Distrik Terhadap Ketahanan Pangan Menggunakan Metode Jaringan Syaraf Tiruan," Telematika, vol. 11, no. 2, pp. 1-11, 2018.

[3] D. Kurniawan, "Design Of Selection Decision Support System Of Superior Rice Breed Using Ahp Method," Konf. Mhs. Sist. Inf., no. 09, 2005.

[4] Y. A. Prasetio, "Selected Decision Support System Of Superior Rice Breed Using Simple Additive Weight (Saw) Method," Simki-Techsain, vol. 02, no. 06, pp. 1-10, 2018.

[5] M. Rendra, H. Roisdiansyah, A. W. Widodo, and N. Hidayat, "Decision Support System for the Selection of Planting Rice Superior Varieties Using AHP and TOPSIS Methods," Pengemb. Teknol. Inf. dan Ilmu Komput., vol. 1, no. 10, pp. 1058-1065, 2017.

[6] F. Frieyadie, "Use Of The Profile Matching Method For The Decision Support System Of Increasing Position In Government Institutions," Paradigma, vol. XVIII, no. March, pp. 75-80, 2016.

[7] R. Astriratma, R. Wardoyo, and A. Musdholifah, "SPK Selection Recommendations for Structural Officials Using the Profile Matching Method (Case Study: Tarakan City Government)," IJCCS, vol. 11, no. 1, pp. 77-88, 2017.

[8] T. Susilowati, E. Y. Anggraeni, W. Andewi, Y. Handayani, and A. Maseleno, "Using Profile Matching Method to Employee Position Movement," Int. J. Pure Appl. Math., vol. 118, no. 7, pp. 415-423, 2018.

[9] R. M. Wibowo, A. E. Permanasari, and I. Hidayah, "Decision Support Systems With Profile Matching Method In Selection Of Achievement Marketing Officer At Bri Katamso Yogyakarta," Int. Conf. Sci. Technol. Humanit., pp. 115-124, 2015.

[10] K. Nisa and E. Sutinah, "Profile Matching for Server and Network Maintenance Vendor Selection Decision Support Systems," J. Inform., vol. 5, no. 2, pp. 262-269, 2018.

[11] Kusrini, Concept and Application of Decision Support Systems. Yogyakarta: Andi Offset, 2007.

[12] David, "Application of Forward Chaining in Expert Systems for Diagnosing Corn Pests and Plant Diseases," Semin. Nas. Inform., 2014. 